\title{
A "infodemia" e a conquista do Estado brasileiro: da Ditadura empresarial-militar ao consenso neoliberal
}

\author{
The "infodemia" and the conquest of the Brazilian State: \\ from the military-business dictatorship to the neoliberal \\ consensus
}

\author{
Bianca Rihan a,* (i) \\ José Raphael Sette ${ }^{\text {b }}$
}

\begin{abstract}
RESUMO: Os recentes debates sobre a epidemia da desinformação, que acomete a cena política mundial nos últimos anos, levam-nos a reflexões sobre o desenvolvimento das tecnologias de informação e comunicação (TICS) durante o processo de reconfiguração do Estado brasileiro. Sob sucessivas rodadas de "modernização conservadora" e tendência monopolística, abordaremos a apropriação informacional nos esteios de nossa última ditadura (1964-1985) e na posterior inserção nacional no propalado processo de neoliberalização, sob um sistema financeiro internacional desregulado.
\end{abstract}

Palavras-chave: Infodemia; Desinformação; Ditadura; Neoliberalismo; Brasil.

ABSTRACT: The recent debates about the disinformation epidemic, which has affected the world political scene in recent years, lead us to reflections on the development of information and communication technologies (TICS) during the reconfiguration of the Brazilian State. Under successive rounds of "conservative modernization" and a monopolistic tendency, we approach the usage of information as a permanence of our last dictatorship (1964-1985) and in the subsequent national insertion in the vaunted process of neoliberalization, beneath a deregulated international financial system.

Keywords: Infodemia; Disinformation; Dictatorship; Neoliberalism; Brazil.

a Departamento de Processos Técnicos e Documentais, Universidade Federal do Estado do Rio de Janeiro, Rio de Janeiro, RJ, Brasil.

b Instituto de Pesquisa e Planejamento Urbano e Regional, Universidade Federal do Rio de Janeiro, Rio de Janeiro, RJ, Brasil.

*Correspondência para/Correspondence to: Bianca Rihan. E-mail: bibirihan@gmail.com.

Recebido em/Received: 29/03/2021; Aprovado em/Approved: 09/06/2021.

Artigo publicado em acesso aberto sob licença CC BY 4.0 Internacional ()(i) 


\section{INTRODUÇÃO}

Buscando relacionar a "objetividade" da informação à dinâmica estrutural de um capitalismo monopolista, dependente e associado, o presente artigo propõe um recorte conjuntural que conecta temporalmente os períodos da ditadura empresarialmilitar brasileira (1964-1985) à globalização neoliberal, a fim de identificar antigas e novas mediações para o que se denomina epidemia informacional.

Suspeitamos que, sob um sistema financeiro mundializado e desregulado, que captura riquezas nacionais, a "infodemia" exerça um papel decisivo sobre o senso-comum, a reorientação de gastos públicos e a própria dimensão do planejamento estatal.

Portanto, a nosso ver, o que se compreende hoje como uma verdadeira infodemia, deve ser investigado como um fenômeno complexo e contraditório, bem mais abrangente do que as limitações em torno da noção de fake news e do papel das plataformas digitais. Mediado por múltiplas determinações, não se restringe ao plano da política strictu sensu e/ou ao desenvolvimento tecnológico como ente isolado, mas aos processos materiais continuados, que produzem as condições de experiências historicamente localizadas.

Sob as balizas dos desdobramentos da teoria social marxiana, trata-se de recobrarmos pressupostos críticos sobre a efetividade da desinformação em nosso país desde o golpe de 1964 até os dias de hoje, visando a superar: i) as abordagens a-históricas sobre o fenômeno da desinformação no Brasil; ii) os tratamentos sobre a questão informacional em nosso tempo alheios à crítica da Economia Política; e iii) as aspirações teórico-práticas das especializações científicas de cunho liberal.

\section{MEDIAÇÕES DIALÉTICAS PARA O ESTUDO DA (DES)INFORMAÇÃO}

Em um rápido retorno a Hegel (2014), acessamos um novo modelo de crítica e sua influência decisiva para a dialética marxiana posterior (Marx, 1978; Netto, 2009). Problematizando a ideia de crítica em Kant - definida como o limite da "sensibilidade" das faculdades do saber, em que se admite a possibilidade apriorística de "coisas em si”, impassíveis às condições de conhecimento; (Kant, 2001) - a compreensão se volta ao "movimento do pensamento", quando a consciência se desacostuma com o objeto ideal e condiciona o imediato sensível à historicidade - passível de novas determinações (Safatle, 2006).

Tal concepção filosófica se diferencia de uma mera descrição de fenômenos, visto que o exercício do pensar contraditório, que questiona o objeto diante de si e o enfrenta, opõe-se à automatização ou à naturalização de sua validade social imediata - uma validade idealizada (idem). Ao superar o idealismo de sistemas conceituais absolutos, que limitam o campo da experiência do saber, o método dialético aponta para o incontornável retorno aos predicados constituintes das contradições do objeto. 
Como em Hegel, a teoria social em Marx se apresenta como um conjunto articulado de explicitações para além das traduções fatorialistas. Porém, diferentemente de seu antecessor, Marx encontrará tal historicidade no exame das relações objetivas de classes e do valor-trabalho sob o crescente predomínio do modo de produção capitalista.

Logo, adotando o método dialético, pautaremos a dita "infodemia” não como categoria etérea, mas desde suas mediações críticas, relacionadas às esferas econômicas, políticas e culturais ao longo do tempo. Destacam-se as reinvenções permanentes das estratégias das classes dominantes nacionais e associadas para garantirem a hegemonia na direção do Estado e o consenso sobre o conjunto da população por meio da atividade cultural/informacional.

A infodemia, enquanto produção social, para além de um diagnóstico patológico, fica então circunscrita ao exame da "economia política da informação, comunicação e cultura” (EPICC) (Bolaño, 1986; Dantas; 1999).

\section{QUE DESINFORMAÇÃO?}

Antes de adentrarmos ao debate proposto, que pretende relacionar a desinformação à reconfiguração do Estado brasileiro em torno de um capitalismo associado, vale abrirmos um parêntese para elucidarmos a concepção de desinformação aqui privilegiada.

Em conferência proferida ao canal do Instituo Brasileiro de Informação em Ciência e Tecnologia (IBICT), em 16/09/2020, o pesquisador Marco Schneider (IBICT)' apresentou um quadro conceitual em torno da categoria. Como se sabe, as disputas sobre a mesma são inúmeras e estão na ordem do dia. Assim, sem pretender ser exaustivo, mas "suficientemente abrangente" para cercar a ideia de desinformação nos estudos em informação e comunicação contemporaneamente, Schneider trabalhou com algumas das clivagens inscritas no termo e com diferentes autores.

Entre as dicotomias possíveis nos usos da desinformação, o pesquisador apresenta questões como a intencionalidade ou a não intencionalidade de uma informação falsa; a desinformação como mentira ou como um hibridismo entre verdade e mentira; e, ainda, a desinformação como verdade descontextualizada, sobrecarga informacional, apelo emocional por manchetes, negação de acesso à verdade, entre outras possibilidades.

Não obstante as tantas leituras sobre o fenômeno desinformacional, assim como sobre a categoria que o investiga, o esforço deste artigo está em destrinchar o problema para

\footnotetext{
${ }^{1}$ SHNEIDER, M. Competência em Informação na Sociedade da Desinformação. [Acessado em 02 de março 2021]. Disponível em:

https://www.youtube.com/watch?v=9W16Uz-

T40A\&ab_channel=InstitutoBrasileirodelnforma\%C3\%A7\%C3\%A30em Ci\%C3\%AAnciaeTecnologia$\underline{I B I C T}$
} 
além de sua aparência imediata, como deixamos explicitado a partir da defesa do método dialético. Portanto, de acordo com Helena Martins, optamos por:

[...] adotar o conceito de desinformação, com o qual se busca ressaltar a intencionalidade na produção e na propagação de informações falsas, equivocadas ou descontextualizadas para provocar uma crise comunicacional e, assim, obter ganhos econômicos e/ou políticos. Nessa perspectiva, a questão da intencionalidade é central. Ela traz à tona agentes e interesses que muitas vezes permanecem ocultos (MARTINS, 2020, s/p).

Logo, frisamos a importância crucial da diferenciação entre os meros repassadores de sofá e os produtores orgânicos da desinformação, ou, conforme os termos de Antonio Gramsci (1987), há que se chamar a atenção para os intelectuais orgânicos² que, incorporados a uma classe social, atuam para o convencimento programático em torno de suas ideias no terreno das lutas sociais, fabricando e disseminando a desinformação que ganhará ecos no "senso comum".

Sob essa ressalva, tanto no Brasil como em vários outros países, os olhares mais diretos se voltam a políticos do alto escalão, incluindo Presidentes da República, que se utilizam "da estratégia da mentira para governar e aplicar medidas que vão de encontro aos interesses das maiorias sociais" (Martins, 2020). Contudo, acreditamos ser necessário ir além, escovando a história a contrapelo, como nos ensina Walter Benjamin (2012), até o reconhecimento de lastros mais profundos, capazes de associar a política aos interesses e ganhos financeiros que advém dessa propagação de desinformação.

Nesse sentido, voltarmos ao momento de ruptura, que atravessou o Estado brasileiro com o golpe de 1964, torna-se uma possibilidade valiosa para o exercício de um olhar menos pontual, menos imediato e mais histórico, contribuindo com um entendimento aprofundado a respeito da seguinte questão: "a quem" e a "que" a desinformação tem servido historicamente?

\section{E O GOLPE DE CLASSE NO BRASIL}

Em 31 de março de 1964, a sociedade brasileira assistiu a um assalto armado ao seu curto processo democrático. Entretanto, o episódio não significou apenas uma ação local, protagonizada por militares nacionalistas. Exercitar uma análise baseada na totalidade e na historicidade nos remete ao movimento de imbricação daquele fato histórico à ação ampliada de nossas classes dominantes, respaldadas pelos interesses do imperialismo norte-americano (Melo, 2013) - vide o programa "Aliança para o

\footnotetext{
2 Ver MARTINS, M. Negacionismo e ideologia: a história do fim da verdade. [Acessado em 08 maio de 2021].

Disponível em: https://www.youtube.com/watch?v=FJRYoCrXp2o\&ab_channel=CanalNIEPMarxCanalNIEP-Marx
} 
Progresso" e a ingerência do governo Lyndon B. Johnson (1963-1969) no Brasil, via embaixada dos EUA.

Nesse processo tão decisivo para a adequação subalterna do Estado brasileiro - que reverbera até hoje na organização social de nosso país - a desinformação teve/tem um papel crucial.

De acordo com Melo (2013), nossa conjuntura era marcada, naquele momento, por um cenário de crises políticas e econômicas. Destacam-se as pressões inflacionárias decorrentes do processo de internacionalização da economia brasileira; a renúncia de Jânio Quadros; a ascensão de João Goulart à Presidência da República; e a polarização da luta de classes, com grande mobilização de movimentos da classe trabalhadora tanto no campo quanto nas cidades e, por outro lado, o avanço das formas organizativas das classes dominantes, sobretudo das frações atreladas ao capital transnacional.

Tais frações, que se internalizam no Brasil desde os anos de $1950^{3}$, passam a se aglutinar, paulatinamente, em torno de entidades e associações que encontraram na fabricação e disseminação da desinformação um de seus principais pilares, e que são fundamentais para entendermos os sentidos de nosso desenvolvimento social.

\section{O Complexo IPES/IBAD}

Na célebre obra, resultante de sua pesquisa de doutorado "1964: A Conquista do Estado, Ação Política, Poder e Golpe de Classe", o cientista político René A. Dreifuss (1981) se dedicou à reconstituição de um passado que, podemos dizer, "permanece presente, ainda que sob novas dinâmicas".

Seu objetivo central foi:

[...] identificar as forças sociais que emergiram na sociedade brasileira com o processo de internacionalização, em sua etapa moderna, e acompanhar sua intervenção no Estado e na sociedade brasileira. Essa história passa pela mediação de atores concretos, de pessoas ou instituições que responderam a valores, objetivos e estratégias das forças sociais que atuam no cenário político, em conjunturas determinadas. O que interessa não é tanto identificar o ator e suas intenções pessoais, mas descobrir no processo histórico o papel e a função das forças sociais e de que formas concretas elas fazem prevalecer seus interesses e suas

\footnotetext{
${ }^{3}$ Em 1955, durante o governo Café Filho (1954-1955), adotou-se a Instrução n¹13, que facilitava a entrada de capital estrangeiro no país. Esta medida foi elaborada pela Superintendência da Moeda e do Crédito (SUMOC) e permitiu a importação de bens de capital à taxa livre de câmbio por estrangeiros, caso estes aceitassem, como pagamento, parcelas de participação na empresa receptora.
} 
concepções nos confrontos com as demais (DREIFUSS, 1981, $\mathrm{s} / \mathrm{p})$.

Nesse sentido, o autor logra uma detalhada apreensão do processo de articulação do golpe de 1964 no seio do que chamou de "elite orgânica", dando-nos a conhecer os procedimentos de recrutamento, estrutura decisória e organização, com o protagonismo de instituições amplamente patrocinadas pelo empresariado nacional e estrangeiro em diversos setores, dentre eles o informacional.

Destaca-se o papel de duas instituições: o Instituto de Pesquisa e Estudos Sociais (IPES) e o Instituto Brasileiro de Ação Democrática (IBAD). Ambas podem ser associadas ao que conhecemos como think tanks 4 e atuaram no acompanhamento dos "grupos de ação que operavam no congresso e junto aos partidos políticos, sindicatos, estudantes, (...) e à mídia", entre outros (Dreifuss, 1981, p. 186)

Um dos recursos mais usados para lograrem seus objetivos foi, justamente, a campanha de desinformação junto à mídia privada, que atuou tanto pela desestabilização do governo João Goulart, quanto para a construção do consenso, em parte da sociedade brasileira, sobre a necessidade de implementação de uma vigorosa reforma administrativa no Estado (Melo, 2013).

Enfatizando "A ação de classe da elite orgânica: a campanha ideológica da burguesia", Dreifuss (1981, p.233) elenca uma série de jornais, jornalistas e grupos de mídia como partícipes centrais da trama do golpe:

O IPES conseguiu organizar um sincronizado assalto à opinião pública, através de seu relacionamento especial com os mais importantes jornais, rádios e televisões nacionais, como: os Diários Associados (poderosa rede de jornais, rádio e televisão de Assis Chateaubriand, por intermédio de Edmundo Monteiro, seu diretor geral e líder do IPES), a Folha de São Paulo (do grupo de Octavio Frias, associado ao IPES), o Estado de São Paulo e o Jornal da Tarde (do Grupo Mesquita, ligado ao IPES, que também possuía a prestigiosa Rádio Eldorado de São Paulo). Diversos jornalistas influentes e editores de $O$ Estado de São Paulo estavam diretamente envolvidos no Grupo Opinião Pública do IPES. Entre os demais participantes da campanha incluíam-se: J. Dantas, do Diário de Notícias, a TV Record e a TV Paulista, ligada ao IPES através de seu líder Paulo Barbosa Lessa, o ativista ipesiano Wilson Figueiredo do Jornal do Brasil, o Correio do Povo do Rio Grande do Sul e O Globo, das Organizações Globo do grupo Roberto Marinho, que também detinha o controle da influente Rádio Globo de alcance nacional.

\footnotetext{
${ }^{4}$ Desde Fahri e Chaia (2020), denominamos "institutos liberais" ou think tanks as organizações políticas sustentadas pelo empresariado internacional e nacional interessadas na propagação do livre-mercado.
} 
Especificamente sobre as estratégias desinformacionais do complexo IPES/IBAD, o autor avalia a presença de propagandas deturpadoras, que "eram basicamente fatuais e continham informação cuidadosamente selecionada à qual se adicionava certa ‘torção”" (idem, p.236); e, também, das "mentiras declaradas ou ficção", exemplificando-as em práticas correntes do jornal O Globo:

Eram também "feitas" em O Globo notícias sem atribuições de fonte ou indicações de pagamento e reproduzidas como informação fatual. Dessas notícias, uma que provocou um grande impacto na opinião pública foi que a União Soviética imporia a instalação de um Gabinete Comunista no Brasil, exercendo todas as formas de pressões internas e externas para aquele fim (idem, p.233).

Como se observa, as empresas de comunicação que, em geral, identificam-se como bastiões da imparcialidade, são muitas delas fomentadoras de um desarranjo informacional de longo prazo, "educando" a população a ver o mundo conforme seus próprios interesses.

Relembremos alguns dos editoriais da grande imprensa, que abriram o mês de abril de 1964, comprovando sua atuação orgânica para o convencimento e a efetividade do golpe:

Golpe? Aqui acusamos o senhor João Goulart de crime de lesapátria. Jogou-nos na luta fratricida, desordem social e corrupção generalizada.

Jornal do Brasil, $1^{\circ}$ de abril de 1964.

Salvos da comunização que celeremente se preparava, os brasileiros devem agradecer aos bravos militares, que os protegem de seus inimigos.

O Globo, $1^{\circ}$ de abril de 1964.

A população de Copacabana saiu às ruas, em verdadeiro carnaval, saudando as tropas do Exército.

O Dia, 2 de abril de 1964.

Se a memória de nossa "transição pactuada” logrou associar os meios de comunicação de massa à censura que sofreram e à resistência que protagonizaram, a análise por uma perspectiva mais ampla deslinda o papel central das empresas de comunicação privadas como principais articuladoras do Golpe de Estado que depôs João Goulart e, sobretudo, como das maiores beneficiárias do regime ditatorial que se seguiu, conforme debateremos adiante.

\section{A era dos monopólios midiáticos brasileiros}

Aproveitando os ensejos de Lenin e Gramsci (Coutinho, 2014, p.120) que categorizaram, respectivamente, como "via prussiana" e "revolução passiva" 
processos históricos que combinaram a modernização com o atraso, ou melhor, "o desenvolvimento das forças produtivas e a conservação de elementos atrasados das relações de produção", muitos autores concordam em classificar a nossa última ditadura como uma etapa da "modernização conservadora a partir de fora" (Fernandes, 1975; Werneck Vianna, 1999). Conforme Coutinho (2014, p.120-121):

\begin{abstract}
Ajustando estruturalmente o Estado brasileiro em proveito dos monopólios e multinacionais, o golpe de 1964 foi uma operação destinada a revolucionar as técnicas de acumulação do capital e, ao mesmo tempo, afastar o fantasma do comunismo e do nacionalismo de esquerda que rondavam a América Latina. A ditadura assumiu, assim, o caráter de uma "contrarrevolução preventiva" que associava a explosão modernizadora com a regeneração de costumes e a estabilidade da ordem [...] associada subalternamente aos interesses imperialistas.
\end{abstract}

Segundo o autor, o regime ditatorial foi a condição política encontrada para o desenvolvimento desse novo padrão de acumulação "na medida em que, por meio da repressão à classe trabalhadora, intensifica a exploração da força de trabalho e possibilita o incremento da taxa de lucro" (idem). Por outro lado, sublinha a impossibilidade de qualquer Estado moderno conservar a hegemonia somente pelo uso da coerção ou da força. Tal afirmação lega importância ao que podemos delimitar como um mercado interno da informação e a construção cotidiana de uma visão "positiva" de mundo que corresponda ao modo de produção capitalista via "aparelhos privados de hegemonia" (Gramsci, 1987).

O fato é que a grande base de apoio ao golpe de 1964 e à ditadura, por meio das estratégias de desinformação e manipulação dos meios de comunicação privados, contribuiu com o alto investimento público no mercado de bens culturais, através da integração do setor infraestrutural da indústria cultural - representando a relação inquebrantável entre as forças políticas e econômicas na condução do Estado ampliado.

As empresas privadas de mídia foram alavancadas através de suporte tecnológico, isenção de impostos, anúncios publicitários, concessões aos aliados políticos e, ainda, pela vista grossa à entrada ilegal de capital estrangeiro no Brasil (FILHO, 2004). Nesse último quesito, não podemos deixar de comentar o emblemático caso da Rede Globo de Televisão, criada em 1965 a partir de um acordo ilegal com o grupo norte-americano Time Life Television 5 , visto que, à época, nossa Constituição proibia a participação de empresas de comunicação estrangeiras no Brasil (Hers, 1987).

Conforme Filho (2004), a família Marinho estabelece sua rede de televisões em 1969 com três emissoras, ao passo que em 1973 já havia angariado onze (hoje são 120,

5 "Grupo da linha mais reacionária e mais retrógrada [ligada ao] do Partido Republicano, exclusivamente interessado em manter, em países como o nosso, bases anticomunistas" (Calmon apud Coutinho, 2014, p. 125). 
incluindo as afiliadas). Isto é, após auxiliar e ser auxiliada pelos sucessivos governos militares, o que era uma empresa jornalística secundária no Rio de Janeiro, tornou-se o mais poderoso grupo midiático do país.

Em sua dissertação de mestrado, Cesar Bolaño (1986, p.3) nos mostra como no curto período entre 1965 e 1970 se consolida a passagem de um mercado comunicacional "relativamente competitivo para outro caracteristicamente oligopólico, fortemente concentrado e centralizado", onde a informação e a cultura se configuram como valiosas fontes de lucro ao grande capital.

\section{PODER (DES)INFORMACIONAL: UM PERCURSO DE JUSTIFICAÇÃO NEOLIBERAL}

Conforme indica a introdução deste artigo, combinando-se ao período ditatorial nacional abordado nas seções anteriores, nosso recorte estendido à contemporaneidade trata de deslindar as contradições do mercado informacional em períodos políticos distintos e conectados à conjuntura externa. Logo, voltamos nossa atenção à virada neoliberal contra o Estado de bem-estar social, a partir da década de 1970. A reconquista da democracia brasileira, coroada em 1985, enfrentaria uma nova dinâmica do capitalismo internacional, operada e desregulada desde Washington. Tal movimento acentua a importância da (des)informação para a propagação coordenada da racionalidade de livre-mercado, que imperará no Brasil e em outros países periféricos.

\section{A construção do consenso neoliberal desde os EUA}

Com o fim da Segunda Guerra (1945), e o marco dos acordos de Bretton Woods (1944), impõe-se uma nova ordem na geopolítica global, reveladora do poderio dos EUA sobre o resto do mundo. Destaca-se, sobretudo, o fato de os EUA terem logrado, a partir dos acordos de 1944, a imposição do câmbio fixo e ajustado, balizado na sua moeda, como lastro de reserva internacional de ouro, fundando-se o padrão dólar-ouro. Com a garantia de reservas metálicas, os EUA passam a concentrar um imenso poder regulador sobre as outras nações, oferecendo liquidez às trocas econômicas subsequentes, principalmente para a reconstrução dos países aliados (Farhi; Cintra, 2009). Tal estratégia seria crucial para os endividamentos nacionais em dólar, reforçando a legitimidade da moeda estadunidense e a dependência econômica externa.

Assim, podemos dizer que ao longo dos primeiros trinta anos do pós-guerra, a chamada "Era de ouro do capitalismo" (Hobsbawm, 1995) foi responsável pela dinamização econômica do Ocidente, com o dólar exprimindo a realização do "valor" nas trocas mundiais.

A hegemonia dos EUA passa, porém, a se ver paulatinamente ameaçada. Internamente, o Estado de bem-estar (welfare state), apesar de relativa seguridade 
social, de leis trabalhistas e de acesso ao consumo, é circunscrito pela intensificação de legítimas reivindicações da sociedade civil, advindas dos movimentos negros, feministas, ecológicos, anti-guerra, etc. Externamente, na medida em que os países aliados se recuperavam do pós-guerra, contestavam também a sua soberania, via compromissos em ouro - como no caso de Charles de Gaulle, na França.

[...] países como a URSS sendo o maior produtor (juntamente com a África do Sul, cujo regime os Estados Unidos "apoiava"), ganhariam muito com um aumento da importância do ouro na economia internacional; e que a França fazia tanta pressão por reformas no sistema que ampliassem o papel do ouro por ser historicamente um país que retinha uma proporção relativamente grande de suas reservas externas em ouro. Certamente não era do interesse nacional do Estado americano em plena guerra fria reforçar o poder desses países em particular (Serrano, 2002, p. 249).

Tal dilema fez com que, no ano de 1971, o presidente Richard Nixon pusesse fim ao padrão dólar-ouro, ganhando respaldo do FMI, em 1973. Tal medida cria um sistema flutuante para a economia, acabando com o lastro universal baseado no ouro e aumentando ainda mais o poder estadunidense, na medida em que o dólar vira a baliza fiduciária internacional.

O movimento de desregulamentação significou, também, nos anos de 1970, a retomada política da austeridade norte-americana contra os avanços distributivos dos anos de bem-estar. De um lado, os apologetas do livre-mercado, como os fundadores da Sociedade Mont-Pèlerin ${ }^{6}$; de outro, a proliferação anárquica da pós-modernidade. Ambos se encontravam na "desestruturação" e no "questionamento radical dos fundamentos de toda a racionalidade moderna", desmontando, no plano sociopolítico, "as referências ideológicas que organizaram todos os projetos e lutas coletivas nos dois últimos séculos" (fiori, 1993, p. 387).

A sociedade de mercado, encarnada pelo "destino manifesto" dos EUA, buscava superar a indisciplina mundial, representada pelo sindicalismo, pelos críticos à Guerra do Vietnã, pelos choques do petróleo e, principalmente, pelo bloco soviético. Para tanto, a informação se apresentava como peça central, combinando-se com o poder do dinheiro e das armas. A partir da década de 1970, a iniciativa pela reconstrução do liberalismo torna-se, então, um grande investimento estadunidense, ganhando

\footnotetext{
${ }^{6}$ A Sociedade Mont-Pèlerin é uma organização internacional e foi fundada em 1947. É composta por diversas personalidades, filósofos e economistas que ganharam notoriedade científica ao se tornaram a matriz especulativa contra a planificação estatal, a universalização de direitos e o Estado de bem-estar social. Destacam-se entre os associados: Friedrich Hayek, Karl Popper, Ludwig von Mises, George Stigler e Milton Friedman. O estudo do neoliberalismo perpassa pela compreensão das diretrizes do grupo, que viriam a influenciar decisivamente o governo estadunidense e depois os países periféricos, como o Chile e o Brasil, através dos institutos liberais e das universidades privadas.
} 
maiores vultos nos anos de 1980 e 1990, sob a dita globalização informacional e financeira.

Nesse cenário, cabe voltarmos, novamente, ao ano de 1971, mais precisamente à publicação confidencial endereçada à Câmara do Comércio dos Estados Unidos (CCEU), escrita por Lewis F. Powell Jr - que logo viria a se tornar juiz associado da suprema corte dos EUA (Braga, 2016). O documento é considerado uma espécie de tratado para a derrubada do welfare, ditando as diretrizes informacionais para a defesa da propriedade privada e do livre-mercado.

Através do "Memorando Powell"7, destacamos alguns pontos que nos ajudam a identificar a virulência da ofensiva neoliberal, desde os EUA. No documento, reivindicase i) o papel do empresariado no financiamento internacional do ideário liberal; ii) a colaboração e a premiação de acadêmicos dos principais centros de pesquisa, convenientes ao liberalismo; iii) a criação de novo corpo de acadêmicos e palestrantes dos ideários da sociedade empresarial; iv) os sistemas de avaliação de textos, publicações, jornais e livros; v) o balanceamento pró-liberal no emprego de docentes e administrativos universitários; vi) a criação de escolas pró-mercado, tipo business schools; vii) o controle da comunicação com o público; viii) a intervenção e o monitoramento nos discursos televisivos sobre as análises negativas acerca do capitalismo; ix) o alinhamento do discurso com outras mídias, como rádio e jornal impresso; $x$ ) o necessário aumento de publicações acadêmicas e periódicos populares sobre a ideologia liberal; $x i)$ os embates com as arenas políticas opostas, como a "doutrina marxista"; xii) as oportunidades de disputa no judiciário, principalmente sobre as "supremas cortes" com "mentalidade ativista"; xiii) o poder dos acionistas de mercado, que, como representantes da classe média rentista, deveriam ser cooptados para ações políticas; e, xiv) a defesa da liberdade pessoal (Powell, 1971 apud Braga, 2016).

Vinte anos depois, em 1990, após o sucesso epistêmico da Escola Austríaca e da Escola de Chicago ${ }^{8}$ de economia - incorporadas por governos como os do general chileno Pinochet (1973-1990), da primeira-ministra britânica Thatcher (1979-1990), e do presidente dos EUA Reagan (1981-1989) -, tais pontos serão traduzidos para a política externa no que se convencionou denominar de "consenso de Washington". Tal "consenso" definiu as diretrizes de governança a serem globalmente exportadas por meio de uma rede de "institutos liberais", ou think-tanks, e aplicadas pelas agências multilaterais nas instituições de Estados periféricos. Como bem define Fiori (1992, p.103):

John Williamson, economista norte-americano, cunhou em 1990, a expressão "consenso de Washington" para referir-se a um conjunto de ideias econômicas e políticas que

7 O nome do documento de Powell era "Memorando confidencial: ataque ao sistema americano de livre empresa", e é datado em 23 de agosto de 1971 e endereçado a Sr. Eugene B. Sydnor Jr., então presidente do comitê de educação da Câmara de Comércio dos Estados Unidos (Braga, 2016).

8 Ambas representativas da ortodoxia liberal. 
condensam [...] para a periferia capitalista o que foram as ideias [...] neoliberais, hegemônicas em quase todo o mundo capitalista, durante os anos 80 [...] chamou esse pacote de ideias de "consenso de Washington", por constituir-se no núcleo central da política econômica externa do governo norte-americano e por ter se transformado em condicionalidade explícita do Fundo Monetário Internacional e do Banco Mundial para a renegociação das dívidas externas e para a readmissão no sistema financeiro internacional dos países que apresentam hoje problemas em seus balanços de pagamento e em suas contas públicas.

O que chama atenção na nova ideologia econômica não é o seu conteúdo, extremamente simples e pouco inovador, é a rapidez com que se transformou em receituário, posto à disposição em qualquer documento burocrático ou editorial da grande imprensa, em versão única [...] De tal forma que, como não poderia deixar de ser, também no Brasil, desde a segunda metade dos anos 80 , se transformou para nossas elites econômicas, políticas e intelectuais em um novo e verdadeiro "elixir da felicidade", capaz de tirar o País de sua prolongada estagflação.

Nesse sentido, é preciso desembaraçar o ardiloso percurso de patrocínio de grandes corporações norte-americanas sobre os institutos liberais na América Latina, que se tornaram ativos durante a ditadura brasileira, ganhando ainda mais validade gerencial com a descentralização estatal.

A decisiva incorporação discursiva neoliberal se precipitará rapidamente na mídia tradicional, na medida em que a abertura ao capital internacional é também constitutiva do financiamento das redes comunicacionais brasileiras, como: Grupo Abril, Grupo Globo, Grupo Folha, Grupo Record, Grupo Bandeirantes de Comunicação, Grupo Objetivo e Grupo Silvio Santos (SBT).

\section{A Constituição de 1988 sob a liberalização}

Tais questões sofrem inflexões imediatas no Brasil desde a abertura democrática, sedimentada pela Assembleia Nacional Constituinte (ANC), em 1987-1988, e pelas eleições diretas para a Presidência, em 1990. Segundo Fagnani (2005) coexistem dois movimentos mais amplos durante a Constituição Federal de 1988 (CF88): um primeiro de "estruturação das bases institucionais, financeiras e de proteção do Estado Social"; e outro de "desestruturação dessa base", que ganha nova dinâmica com a predominância do capital portador de juros, ancorado na publicidade televisiva. A dialética entre esses dois processos resulta na complexidade constitucional e social dos anos 1990, 2000 e 2010, em que há severo predomínio das "contrarreformas, liberais e conservadoras", de reação midiática ao gasto social e à institucionalidade solidária da nova Constituição. 
Segundo o autor, as rodadas liberalizantes seriam sucessivas e permanentes, alterando certo otimismo social dos anos de abertura. A primeira ocorre via executivo federal já no governo Sarney, com o abalo dos quadros orçamentários progressivos da Saúde, da Previdência Social e da Educação, do Seguro-Desemprego e da Suplementação Alimentar, até 1990. A segunda se daria entre as eleições da década de 1990 e a sujeição macroeconômica aos países centrais, por conta da dívida externa. O texto da constituinte, por sua vez, seria paulatinamente alterado, refletindo uma conjuntura desfavorável, de maior concorrência interestatal, desregulamentação cambial, privatização das empresas públicas e arrocho salarial.

Advinda da formação de monopólios durante a ditadura, a falta de regulamentação sobre a comunicação social também viria a contrariar os preceitos democráticos dos artigos constitucionais ${ }^{9}$, como o reproduzido abaixo:

Art. 220. $\S 5^{\circ}$ Os meios de comunicação social não podem, direta ou indiretamente, ser objeto de monopólio ou oligopólio.

Constituição da República Federativa do Brasil, 1988.

Nesse sentido, a caracterização da "comunicação" como "social" acabou por escapar à prática, prevalecendo a atividade econômica sobre o serviço público, e/ou a coordenação política liberal sobre a pluralidade informacional, mesmo que em novo regime político, que responde por democracia.

Por sua vez, trabalhando arduamente o "interesse no desinteresse" (Bourdieu, 1994), os experts de mercado se solidificaram em uma rede transnacional de think-tanks, sob os conhecidos arquétipos dos "institutos liberais" (Faria; Chaia, 2020). Esses se mostraram massivamente atuantes no desenvolvimento acadêmico, institucional, político e filosófico dos países periféricos a partir da década de 1990. Suas produções, enquanto corpo técnico, são respaldadas e propaladas por agências multilaterais como o Fundo Monetário Internacional (FMI), o Banco Mundial (BM), o Banco Internacional para Reconstrução e Desenvolvimento (BIRD) e a Organização das Nações Unidas $(\mathrm{ONU})^{10}$.

Não é difícil encontrarmos os ortodoxos da Sociedade Mont-Pèlerin, da Escola Austríaca ou da Escola de Chicago prestigiados entre ministros da Fazenda do Brasil, como Paulo Guedes (2019-) e Pedro Malan (1995-2003), ou entre os ex-presidentes do Banco Central da era Fernando Henrique Cardoso (FHC), como Armínio Fraga (19992003) e Gustavo Franco (1997-1999) - ambos ligados aos institutos liberais brasileiros, à prestação de consultorias bancárias e aos investimentos financeiros privados.

\footnotetext{
9 Ver artigos 220, 221, 223 e 224.

10 Vale ressaltar que o Banco Mundial, de 1946 até 2019, nunca teve um presidente que não fosse estadunidense, e sua sede como a do FMI estão localizadas em Washington D.C., EUA.
} 
Sob diretrizes mais gerais, os think-tanks ${ }^{11}$ e a mídia nacional se combinam em ficcionar, controlar e distorcer a realidade como modo de enfrentamento: i) da pluralidade da democracia; ii) da discussão econômica, pautando ideias "puras" de mercado; iii) da seguridade do trabalho; iv) do Estado social, por meio de uma pedagogia de livremercado; v) da decomposição dos gastos públicos, em prol da acumulação privada; vi) da justiça social, indicando a meritocracia empreendedora particularista; e vii) da empresa pública, pela defesa da privatização.

\section{Desinformação contra a democracia}

Ainda na primeira metade da década de 1990, concomitantemente à dita globalização financeira, mercantil e intelectual, assistiu-se a abertura comercial da World Wide Web (WWW) que, de início, despertou as especulações mais otimistas quanto às possibilidades de uma grande "praça pública" online. A socialização prometida pela internet nos remete às descrições de Jorge Luís Borges $(1976$, p.65) acerca da "Biblioteca de Babel":

Quando se proclamou que a Biblioteca abarcava todos os livros, a primeira impressão foi de extravagante felicidade. Todos os homens sentiram-se proprietários de um tesouro intacto e secreto. Não havia problema pessoal ou mundial cuja eloquente solução não existisse [...] $O$ universo estava justificado.

No entanto, sob as lentes da crítica da economia política, podemos afirmar que a internet, identificada, num primeiro momento, como vigorosa ferramenta de "valor de uso" para o "ser social”, revelou-se, em curto prazo, um meio eficaz para o lucro privado por meio da publicidade, da concentração informacional e da propagação de desinformação.

Desde a Califórnia (EUA), e com o incentivo financeiro do governo (via Defense Advanced Research Projects Agency, a DARPA, por exemplo), as empresas do Vale do Silício se consolidaram como potências tecnológicas internacionais, desenvolvendo softwares, hardwares e hospedagem de dados estruturados e microdados, com diretrizes oligopólicas ${ }^{12}$. Os dados produzidos por indivíduos em rede global são, primeiramente, armazenados e, em seguida, processados pela orientação política e econômica de quem detém a informação.

\footnotetext{
${ }^{11}$ A partir de Farhi e Chaia (2020), destacamos no Brasil: Instituto Liberal do Rio de Janeiro; Instituto Millenium; Instituto de Estudos Empresariais; Instituto de Formação de Líderes; e Instituto Ludwig Von Mises Brasil. Por sua vez, estes institutos podem ser associados às redes internacionais: Rede Atlas, Rede Relial, Rede FIL e Rede Hacer.

${ }^{12}$ Segundo a Forbes Global 2020, figuram entre os sessenta maiores valores de mercado mundiais conglomerados de origem norte-americana ligados à comunicação, como: Apple (9), AT\&T (11), Google (13), Microsoft (13), Verizion (20), Amazon (22), Facebook (39) e IBM (51). [Acessado em 28 de fevereiro 2021].

Disponível em: https://www.forbes.com/global2000/\#6d33fe30335d
} 
A dissuasão da pluralidade informacional seria cooptada pelo "filtro" de algoritmos, publicidades, sites pagos de streaming, redes sociais, plataformas de mensagens instantâneas e nova ofensiva de mercado sobre a propriedade intelectual de softwares, por exemplo. Em países periféricos, como o Brasil, de baixa autonomia tecnológica, a entrada de tais plataformas e capitais, combinadas com a concentração midiática nacional, serviria como um potente instrumento de espionagem políticoempresarial e dominação para a despolitização coletiva, gerando engajamento via desinformação.

O recobrado controle da narrativa no Brasil se agrava nos anos 2000 e 2010, quando, sob o neoliberalismo informacional, a América Latina consegue eleger governos progressistas ligados à esquerda.

As disputas políticas entre classes são ainda mais dramatizadas pela crise financeira de 2008 e a combinação da desinformação com a perseguição jurídica contra figuras de Estado, definida como lawfare ${ }^{13}$ (Valim, 2017). Tal processo inconstitucional é sustentado na validação midiática, justamente, a partir da celebração de seu modus operandi pelos grupos informacionais nacionais, pelos institutos liberais brasileiros, por frações do empresariado e pelas figuras partidárias que enxergavam nessa processualidade assimétrica uma oportunidade eleitoreira. Há, portanto, uma objetividade social que combina campos e frações da sociedade civil na disputa do Estado.

A concepção de Estado ampliado, conforme Gramsci, pode então ser analisada, no caso brasileiro contemporâneo, a partir das frações de classe nacionais, da ingerência do capital internacional, do Estado imperialista, dos grupos midiáticas nacionais e dos usos de plataformas internacionais. A localização de tais hierarquias da ação e da intervenção engendram determinações concretas sobre o conturbado movimento reacionário que se instaura contra um determinado governo - no caso, o executivo do Partido dos Trabalhadores (PT), desde 2003, e que se impõe, definitivamente, em 2016, com o golpe a então presidenta Dilma Rousseff e a posterior prisão do ex-presidente Lula, em 2018, quando este liderava a corrida presidencial.

A revelação da cadeia desinformacional tem sido possibilitada pela mídia independente, como na reportagem "Vaza Jato", do jornal on-line The Intercept_Brasil14 e se refere às "discussões internas e atitudes altamente controversas, politizadas e legalmente duvidosas da força-tarefa da Lava Jato ${ }^{15}[. .$.$] em$

${ }^{13}$ Segundo Valim (2017), o termo lawfare, em inglês, diz respeito à combinação do termo law, lei, com warfare, regime de guerra. Sua processualidade está relacionada ao uso do Direito como forma de perseguição e destruição política contra um eventual "inimigo". Há, portanto, uma descaracterização do processo legal, indicando a falta de isonomia nos ritos do julgamento, como: grampos telefônicos contra a defesa dos acusados, relacionamento espúrio entre acusadores e juízes, manipulação de provas, ocultação de indícios de inocência e desmoralização através de parcerias midiáticas.

${ }^{14}$ As reportagens tiveram início em 09 de junho de 2019 e contaram com o vazamento de mensagens hackeadas a partir da plataforma Telegram. [Acessado em 06 de março 2021]. Disponível em: https://theintercept.com/2019/06/og/editorial-chats-telegram-lava-jato-moro/

${ }^{15}$ Operação da Polícia Federal brasileira e do Ministério Público Federal. 
colaboração com o atual Ministro da Justiça, Sérgio Moro ${ }^{16 " . ~ A t e ́ ~ a g o r a, ~ e s t a ̃ o ~}$ compiladas cento e seis publicações que envolvem: os monopólios midiáticos (como a Rede Globo), os institutos liberais (como o Movimento Brasil Livre - MBL), o Superior Tribunal Federal (STF), o Ministério Público Federal (MPF), a Polícia Federal (PF), parcelas do empresariado brasileiro, diversos dirigentes políticos e o serviço de inteligência dos EUA (como o Federal Bureau of Investigation, o FBI) - entre outros.

A construção de uma diretriz persecutória ganharia respaldo ostensivo na mídia monopolista desde o julgamento da Ação Penal 470 - o dito "mensalão" -, que começou em 2005, mas transcorreu no STF apenas em 2012. Através dos deslocamentos das pautas originais, a narrativa pró-golpe também assume protagonismo na condução midiática dos movimentos de 2013, com ampla cobertura nacional. Posteriormente, tem desdobramento na "Operação Lava Jato", em 2014, com a ativa adesão promocional do empresariado nacional, representado pela FIESP e FIRJAN ${ }^{17}$.

No limiar da produção ideológica de desinformação, sob a doutrina neoliberal e o conservadorismo classista, os desdobramentos da CPMI das Fake News, em 2018, ratificaram o renovado papel da direita brasileira: a propagação de informações equivocadas ou descontextualizadas, com ancoragem no capital internacional. Nesse sentido, todas as plataformas e grupos comunicacionais exerceram axial importância como meio ativo de proliferação acusatória contra a democracia nacional - desde os disparos no WhatsApp e Twitter, até o papel ativo dos jornais e das emissoras de televisão e rádio.

Por fim, mas não menos importante, vale lembrar que, naquela conjuntura, o candidato adotado pelas frações burguesas dirigentes era um ex-capitão do Exército, entusiasta declarado da ditadura. A entrada do "partido armado" no pleito de 2018 ficou mais evidente com o recém lançamento do livro "General Villas Bôas: conversa com o comandante", organizado por Celso Castro (2021). Como afirma o autor, o livro diz respeito à participação de Villas Bôas ${ }^{18}$ nos "eventos políticos decisivos, com atenção especial ao período em que foi comandante" - ressaltando a atuação "moderadora" das Forças Armadas (FA) na eleição de 2018. Hoje, segundo dados do Tribunal de Contas da União (TCU, 2020), ocupam cargos civis no Governo Federal aproximadamente seis mil militares.

O resultado mais geral da (re)conquista do Estado brasileiro - entre a articulação militar e frações da burguesia nacional-associada - foi o êxito em criminalizar a oposição partidária, desinformar a população acerca do conhecimento políticoeconômico e promulgar as reformas austeras constitucionais e administrativas, com ancoragem simbólica na isonomia tecnocrata militar. Como ponto de chegada,

\footnotetext{
${ }^{16}$ Juiz da ação que prendeu o ex-presidente Lula da Silva e que viria a se tornar ministro do governo Bolsonaro, já em 2018.

17 Respectivamente, Federação das Indústrias do Estado de São Paulo e Federação das Indústrias do Estado do Rio de Janeiro.

${ }^{18}$ Comandante do Exército Brasileiro entre 2015 e 2019.
} 
ressaltamos o sucesso do empreendimento neoliberal multilateral, como matriz especulativa contra o desenvolvimento social nacional e soberano.

Aspectos diretos da vitória da acumulação capitalista e da transferência de valor internacional, estão explícitos: na Emenda Constitucional n95, a PEC do Teto de Gastos de 2016, que congelou o investimento em educação e saúde por vinte anos; na Reforma Trabalhista contra a seguridade do emprego, de 2017; na Reforma da Previdência, de 2019; no recorde de informalização do emprego nacional (IBGE, 2020), explorado pelas plataformas internacionais Uber, Ifood e Rappi; na "independência" da presidência do Banco Central; na dolarização da economia nacional, com a abertura de conta corrente em moeda estrangeira; no desmonte das empresas públicas, como a Petrobrás, e a venda de bacias de petróleo e refinarias às empresas estrangeiras; no aumento da desigualdade nacional e da concentração de renda (IBGE, 2020); no congelamento de salários de servidores públicos por 15 anos; e no tratamento omisso, desinformacional e até mesmo criminoso da pandemia do Sars-CoV-2, que até a redação desse artigo havia matado mais de 473.000 brasileiros (OMS, 2021).

\section{CONSIDERAÇÕES FINAIS}

A partir da aproximação à crítica à economia política, procuramos demonstrar que o tema da desinformação e o seu sintoma infodêmico devem ser analisados em relação às engrenagens do modo de produção capitalista e seus agentes orgânicos ao longo da história. Distantes das determinações concretas que se colocam à unidade do real, como conjunto complexo e contraditório, as pesquisas sobre a informação só poderão acessar a superfície da questão. Desse modo, concentramos nossos esforços em circunscrever, ainda que brevemente, os meandros da concentração informacional ao longo do processo de reconfiguração do Estado brasileiro em torno da internacionalização de capitais. Ressalta-se os oligopólios midiáticos erguidos durante nossa última ditadura, até os novos contornos da concentração informacional, via plataformas digitais e financeiras.

Compreendendo o problema para além do isolamento de nichos acadêmicos específicos, chamamos a atenção do campo da Ciência da Informação $(\mathrm{Cl})$ para a necessidade em não abandonarmos as correlações entre o desenvolvimento da sociedade de mercado e da racionalidade para os "valores de troca", em que a informação exerce papel estruturante de publicização e legitimação. Trata-se de evidenciarmos os obstáculos imputados ao devir social e ao bem comum, desde a concentração dos meios, em que impera a lógica de ganho de classe: monetária, territorial e simbólica. Quando se compreende minimamente os mecanismos de transferência de valor e exploração entre nações e classes nacionais, a dimensão da economia política para a transformação da realidade passa a exercer centralidade.

Filiando-nos aos avanços da EPICC, a agenda de pesquisa sobre a desinformação e a infodemia se amplia à objetividade dos agentes com capacidade de mando e decisão. Identificar a produção dessas determinações entre empresariado e Estado se torna 
campo fértil para o estudo informacional. Por ora, cabe sublinharmos que a regulação midiática nacional carece de autodeterminação, assim como carecemos de um projeto de soberania nacional plural e redistributivo.

\section{REFERÊNCIAS}

BENJAMIM, W. Magia e técnica, arte e política: ensaios sobre literatura e história da cultura. $8^{\text {a }}$ Ed. - São Paulo: Brasiliense, 2012.

BOLAÑo, C. R. S. Mercado brasileiro de televisão: uma abordagem dinâmica. Dissertação. UNICAMP, Instituto de Economia, Campinas, 1986.

BORGES, J. L. Fiç̧ões. $1^{a}$ Edição, Editora Globo, Rio Grande do Sul, 1970.

BOURDIEU, P. O campo científico. In: ORTIZ, Renato (Org.). A sociologia de Pierre Bourdieu. São Paulo: Ática, 1994.

BRAGA, H. Memorando Powell. IN: Marx e Marxismo. Publicação do Núcleo Interdisciplinar de Estudos sobre Marx e Marxismo - v.4, n.7, Niterói: UFF, 2016.

CASTRO, C. C. P. General Villas Bôas: conversa com o comandante. Rio de Janeiro, Editora FGV, 2021.

COUTINHO, E. G. A comunicação do oprimido e outros ensaios. - 1. Ed. - Rio de Janeiro: Mórula, 2014.

DANTAS, M. Capitalismo na Era das Redes: trabalho, informação, valor no ciclo da comunicação produtiva. In: LASTRES, H; ALBAGLI, S. Informação e globalização na Era do Conhecimento. Rio de Janeiro: Editora Campus, 1999.

DREIFUSS, R. A. 1964: A Conquista do Estado. Ação Política, Poder e Golpe de Classe. $3^{\text {a }}$ Ed, Petrópolis, Editora Vozes, 1981.

FAGNANI, E. Política social no Brasil (1964-2002): entre a cidadania e a caridade. Campinas, 2005.

FAHRI, M. e CINTRA, M. A. M. A arquitetura do sistema financeiro internacional contemporâneo. Revista de Economia Política, v.29, n.3 (115), 2009.

FARIA, A. L. B. e CHAIA V. Os institutos liberais e a consolidação da hegemonia neoliberal na América Latina e no Brasil. Cadernos Metrópole, São Paulo, v.22, n.49, 2020.

FERNANDES, F. Capitalismo Dependente e Classes Sociais na América Latina. $2^{\mathrm{a}}$ edição. Rio de Janeiro: Zahar, 1975.

FILHO, L. L. Quarenta anos depois, a TV brasileira ainda guarda as marcas da ditadura. Revista USP, São Paulo, n.61, 2004. 
FIORI, J. L. Sobre a "crise contemporânea": uma nota perplexa. Síntese Nova Fase, Belo Horizonte, v.20, n.62, 1993.

FIORI, J. L. A sonolência da razão. Revista Indicadores Econômicos, Porto Alegre, v.19, 1992.

GRAMSCI, A. Os intelectuais e a organização da cultura. Rio de Janeiro: Civilização Brasileira, 1987.

HEGEL, G. W. F. Fenomenologia do Espírito. - 9. Ed. - Petrópolis, RJ: Vozes : Bragança Paulista : Editora Universitária São Francisco, 2014.

HERS, D. A História Secreta da Rede Globo. Porto Alegre: Tchê Editora, 1987.

HOBSBAWM, E. A Era dos Extremos: o breve século XX: 1914-1991. - São Paulo: Companhia das Letras, 1995.

IBGE. PNAD Contínua. 2020. [Acessado em 12 de março 2021]. Disponível em: https://www.ibge.gov.br

KANT, I. Crítica da razão pura. - Lisboa: Edição Fundação Calouste Gulbenkian, 5 a Ed., 2001.

MARTINS, H. Muito além das fake News: a desinformação em meio à crise social. Le Monde Diplomatique Brasil. Brasil, Arcevo Online, 9 de julho de 2020. [Acessado em 13 de março 2021]. Disponível em: https://diplomatique.org.br/a-desinformacao-em-meioa-crise-social/

MARTINS, M. Negacionismo e ideologia: a história do fim da verdade. Canal NIEP-Marx, Youtube, 2020. [Acessado em 08 de maio 2021]. Disponível em:

https://www.youtube.com/watch?v=FJRYoCrXp2o\&ab_channel=CanalNIEP-

MarxCanalNIEP-Marx

MARX, K. Para a Crítica da Economia Política. São Paulo: Abril Cultural. (Col. Os Pensadores), 1978.

MELO, D. B. Crise orgânica e ação política da classe trabalhadora brasileira: a primeira greve geral nacional (5 de julho de 1962). Tese (Doutorado). Instituto de Ciências Humanas e Filosofia, Departamento de História, Universidade Federal Fluminense. Niterói, 2013.

NETTO, J. P. Introdução ao método da teoria social. IN: Serviço social: direitos sociais e competências profissionais. Brasília: CFEES/ABEPSS, 2009.

OPAS/OMS. Folha informativa COVID-19. 2021. [Acessado em 12 de março 2021]. Disponível em: https://www.paho.org/pt/brasil

SAFATLE, V. A paixão do negativo: Lacan e a dialética. - São Paulo: Editora UNESP, 2006.

SCHNEIDER, M. Competência em Informação na Sociedade da Desinformação. IBICT, YouTube, 2020. [Acessado em 02 de março 2021]. Disponível em: 
https://www.youtube.com/watch?v=9WI6Uz-

T40A\&ab_channel=InstitutoBrasileirodelnforma\%C3\%A7\%C3\%A3oemCi\%C3\%AAnciaeTe cnologia-IBICT

SERRANO, F. Do ouro imóvel ao dólar flexível. Economia e Sociedade, Campinas, v. 11, n. 2 (19), 2002.

TCU. Memorando $n^{\circ} 57 / 2020-S e g e c e x$. Tribunal de Contas da União, Secretaria-Geral de Controle Externo, 2020.

VALIM, R. Estado de exceção: a forma jurídica do neoliberalismo. São Paulo: Contracorrente, 2017.

WERNECK VIANNA, L. Liberalismo e Sindicato no Brasil. $4^{\text {a }}$ edição. Belo Horizonte, Editora UFMG, 1999. 